\title{
E2F Mediates Dihydrofolate Reductase Promoter Activation and Multiprotein Complex Formation in Human Cytomegalovirus Infection
}

\author{
MICHAEL WADE, ${ }^{1,2}$ TIMOTHY F. KOWALIK, ${ }^{1}$ MARIA MUDRYJ, ${ }^{3}$ ENG-SHANG HUANG, ${ }^{1,2,4,5}$ \\ AND JANE CLIFFORD AZIZKHAN ${ }^{1,2,6,7 *}$ \\ Lineberger Comprehensive Cancer Center, ${ }^{1 *}$ Curriculum in Genetics, ${ }^{2}$ and Departments of Pharmacology, ${ }^{6}$ \\ Pediatrics, ${ }^{7}$ Microbiology and Immunology, ${ }^{4}$ and Medicine, ${ }^{5}$ University of North Carolina, Chapel Hill, \\ North Carolina 27599, and Section of Genetics, Department of Microbiology and Immunology, Howard \\ Hughes Medical Institute, Duke University Medical Center, Durham, North Carolina $27710^{3}$
}

Received 29 April 1992/Returned for modification 2 June 1992/Accepted 8 July 1992

\begin{abstract}
The adenovirus immediate-early protein E1A activates the adenovirus E2 promoter and several cellular gene promoters through transcription factor E2F. The immediate-early proteins of human cytomegalovirus (HCMV) can complement an E1A-deficient adenovirus mutant and activate the adenovirus E2 promoter. HCMV also has been shown to activate the adenovirus $\mathrm{E} 2$ promoter. On the basis of these findings, we have investigated whether HCMV can activate the promoter of the cellular dihydrofolate reductase (DHFR) gene, which requires E2F binding for maximal promoter activity. We show that HCMV activates the DHFR promoter and that products of the HCMV major immediate-early gene region mediate the activation of the promoter specifically through the E2F site. We used gel mobility shift assays to search for potential molecular mechanisms for this activation and found an "infection-specific" multimeric complex that bound to the E2F sites in the DHFR and E2 promoters in extracts from HCMV-infected cells but not in extracts from uninfected cells. Several antibodies against HCMV immediate-early gene products had no effect on this infection-specific complex. Subsequently, the complex was found to contain E2F, cyclin A, p33 ${ }^{\text {cdk2 }}$, and p107 and to be similar to S-phase-specific complexes that recently have been identified in several cell types. A functional role for the binding of the cyclin A-p33 ${ }^{\text {cdk2 }}$ complex to cellular gene promoters has yet to be demonstrated; however, HCMV infection causes the induction of both cellular DNA replication and transcription of growth-related genes containing E2F sites in their promoters. The findings described above therefore may relate to both of these effects of HCMV infection. We also provide evidence that some of the molecular events associated with adenovirus infection are different from those associated with HCMV infection.
\end{abstract}

Transcription factor E2F, first identified as a HeLa cell factor that binds to the adenovirus E2 promoter, has since been implicated in viral modulation of the expression of several cellular growth-controlled genes $(41,43,58,86)$. Recent studies of E2F have focused on its association in multimeric DNA binding complexes with other cellular proteins at specific times during the cell cycle. For example, E2F associates with the underphosphorylated G1 form of tumor suppressor protein $\mathrm{Rb}$ in a complex that appears to down-regulate transcription $(9,19-21,42,78)$. Other studies have revealed in several cell types an $S$-phase-specific complex that includes at least four proteins: E2F, retinoblastoma-related protein p107, cyclin A, and a cyclin A-regulated protein serine-threonine kinase, p33 ${ }^{c d k 2}$ (for "cyclindependent kinase" or "cell division kinase"), that is homologous to another cyclin-regulated master cell cycle kinase, p34 $4^{c d c 2}(19,24,28,30,65,69,78)$. There has also been a report that both cyclin $\mathrm{A}$ and $\mathrm{Rb}$ are components of a DNA binding complex with an E2F-like activity, termed DRTF-1 (10). Although the E2F-p107-cyclin A-cdk2 complex has been shown to have histone kinase activity in vitro (24), an in vivo role for E2F-associated kinase activity has not been demonstrated.

Among the cellular gene promoters modulated by E2F is that of dihydrofolate reductase (DHFR). The DHFR enzyme

\footnotetext{
* Corresponding author.
}

is required for DNA synthesis because it provides reduced folates in the biosynthetic pathways for nucleotides. A previous study of the hamster DHFR promoter demonstrated that E2F, which binds to an overlapping dyad sequence element just downstream of the major transcription start site, is required for maximal basal transcription (14). Another required factor is Sp1, an abundant and wellcharacterized mammalian protein that binds to four upstream GC-rich elements in the hamster DHFR promoter $(14,15,83)$.

Because of the demonstrated ability of human cytomegalovirus (HCMV) to induce the transcription of cellular genes associated with DNA replication, we examined the activation of the DHFR promoter and binding to the DHFR E2F site during infection by HCMV. There were several reasons to suspect that E2F could be involved in the cellular response to HCMV. First, previous work showed that immediate-early (IE) proteins of HCMV can complement an E1A-deficient adenovirus mutant and induce transcription from the adenovirus E2 early promoter $(40,79,85)$. In addition, we noted potential E2F binding sites in regions of the promoters of at least three HCMV early genes that are important for transactivation by HCMV IE protein(s) during a productive viral infection $(54,55,62,80,89)$. Finally, the recently discovered association of $E 2 F$ with proteins linked to cell cycle control implied that HCMV, a potentially transforming herpesvirus that activates cellular DNA synthesis and proliferation, could act to alter the interactions 
among E2F and other proteins $(4,5,23,32,81,82$; reviewed in reference 2).

Previous work had shown that adenovirus stimulates E2F binding activity, dependent on the expression of the viral E1A protein. The formation and functional role of an E1Adependent heteromeric complex containing E2F and the viral E4 protein on the adenovirus E2 early promoter have been investigated extensively. However, adenovirus activation of cellular promoters through E2F apparently does not involve the formation of heteromeric complexes but instead is associated with an induction of the binding activity of free E2F-that is, E2F that is not complexed with another protein $(7,41,74,86)$.

Despite the apparent functional similarities between adenovirus E1A and HCMV IE protein(s), there has not been a study of the specific role of E2F in the HCMV activation of gene promoters, nor has there been an examination of E2F binding activity during an HCMV infection. We report here that HCMV activates the DHFR promoter and that the activation can be mediated through the E2F site by viral IE gene products. Furthermore, we show that HCMV infection is associated with the formation of an E2F-containing heteromeric complex that is dependent on a single E2F recognition sequence. We have termed this complex "infection specific" throughout this report, but our results indicate that the four known components of the HCMV-induced complex-E2F, cyclin A, p33 ${ }^{c d k 2}$, and p107-are also part of a complex that binds specifically to E2F sites during the $S$ phase of the cell cycle. These findings implicate a cellular transcription factor as a target for HCMV activation and may relate to earlier reports that HCMV stimulates cellular DNA synthesis and proliferation $(4,23,81,82)$.

(M.W. performed this work in partial fulfillment of the requirements for a Ph.D. degree from the Curriculum in Genetics, University of North Carolina, Chapel Hill.)

\section{MATERIALS AND METHODS}

Cell culture and nuclear extract preparation. Newborn human foreskin fibroblast (NHF) cells were kindly provided by W. Kaufman (University of North Carolina, Chapel Hill). NHF, Cos-1, and human embryonic lung (HEL) cells were cultured in Eagle's minimal essential medium supplemented with $10 \%$ fetal bovine serum (GIBCO) and penicillin-streptomycin. NHF and HEL cell nuclear extracts were prepared as described previously $(14,25)$, except that cells were mechanically scraped from monolayer cultures in $\mathrm{Ca}$ - and Mg-free Hanks balanced salt solution plus $25 \mathrm{mM}$ EDTA. For synchronization experiments, HEL cells in mid-log phase were serum starved for $36 \mathrm{~h}$ by reducing the medium supplement to $0.5 \%$ calf serum. Serum was added to starved cells to a final concentration of $20 \%$, and S-phase extracts were prepared $18 \mathrm{~h}$ later.

Virus infections. HCMV Towne strain (passage 37) stocks were prepared as described previously (48). Virus was added to NHF or HEL cells ( $80 \%$ confluence) at a multiplicity of infection of 5 and adsorbed for $2 \mathrm{~h}$. Infecting fluids containing no virus particles were added to uninfected or mockinfected cells.

Gel mobility shift assays. Gel mobility shift assays were performed essentially as described previously (43). The reaction mixture contained 0.1 to $0.5 \mathrm{ng}$ of labeled DHFR or E2 promoter fragment in $20 \mu \mathrm{l}$ of binding reaction buffer ( 20 mM N-2-hydroxyethylpiperazine- $N^{\prime}$-2-ethanesulfonic acid [HEPES] [pH 7.8], $1 \mathrm{mM} \mathrm{MgCl}_{2}, 0.1 \mathrm{mM}$ EDTA, $40 \mathrm{mM}$ $\mathrm{KCl}, 0.5 \mathrm{mM}$ dithiothreitol, $2 \mu \mathrm{g}$ of salmon sperm DNA, 60 $\mu \mathrm{g}$ of bovine serum albumin, $1.5 \%$ Nonidet P-40 [Sigma], $1 \%$ Ficoll) and 3 to $15 \mu \mathrm{g}$ of nuclear protein. For deoxycholate (DOC) dissociation experiments (12), Nonidet P-40 was left out of the reaction buffer until the reaction mixture had been incubated in the presence of DOC (final concentration, $0.25 \%$ ) for 10 to $15 \mathrm{~min}$, after which Nonidet P-40 was added to a final concentration of $1.5 \%$. When needed, antibodies or antisera were added to the reaction mixture in the presence of cell extract, and a labeled DNA probe was added immediately afterward. Binding reactions proceeded at room temperature or at $4^{\circ} \mathrm{C}$, and gels ( $4 \%$ polyacrylamide; acrylamide-bisacrylamide, 29:1) were run for 60 to $80 \mathrm{~min}$ at $4^{\circ} \mathrm{C}$ before being dried and autoradiographed.

In vitro translation of E1A. Plasmids encoding the wildtype and 928 point mutant $12 \mathrm{~S}$ E1A proteins (73) were transcribed in vitro with SP6 polymerase and capped before in vitro translation with a reticulocyte lysate kit (Promega Biotec) as described previously $(65,73)$. The amounts of translation products were quantitated by parallel translation reactions in the presence of $\left[{ }^{35} \mathrm{~S}\right]$ methionine and then sodium dodecyl sulfate-polyacrylamide gel electrophoresis and autoradiography of dried gels. Aliquots from unlabeled translation reaction mixtures containing equal amounts of wildtype or mutant $12 \mathrm{~S}$ E1A protein were added to gel mobility shift reaction mixtures.

Antisera and antibodies. Rabbit antiserum against cyclin A was provided by J. Pines and T. Hunter (72). Another anti-cyclin $\mathrm{A}$ rabbit antiserum and affinity-purified rabbit antibodies against p107 were a gift from J. Schwarz. Rabbit antisera against $\mathrm{p} 34^{c d c 2}$ and $\mathrm{p} 33^{c d k 2}$ were provided by $\mathbf{M}$. Pagano and P. Jansen-Durr $(69,70)$. Mouse antiserum against p33 $3^{\text {cdk2 }}(87)$ and monoclonal antibody XZ77, which recognizes Rb but not p107 (45), were gifts from Ed Harlow. Polyclonal antibodies against HCMV major IE gene region products were provided by R. Jupp and J. Nelson, and an anti-HCMV IE 1 and 2 monoclonal antibody was obtained from Dupont (catalog no. 9221). Affinity-purified rabbit antibodies against cyclin B and p34 $4^{c d c 2}$ and additional antibodies against $\mathrm{Rb}$ were purchased from Oncogene Science.

Transient expression assays. NHF cells were transfected by the calcium phosphate method (35). Cos- 1 cells were transfected with Lipofectin (BRL) in accordance with the manufacturer's protocol. In each case, cells were transfected at 30 to $50 \%$ confluence. In all chloramphenicol acetyltransferase (CAT) assay experiments, the total amount of cotransfected DNA was normalized with pUC18. Cells were harvested at various times and lysed by repeated freezing-thawing, and clarified supernatants were assayed for CAT activity (34). Levels of activity were quantitated by liquid scintillation counting of $\left[{ }^{14} \mathrm{C}\right]$ chloramphenicol converted to acetylated forms after autoradiography of thinlayer chromatography plates.

Plasmids. A plasmid expressing the HCMV IE 1 and 2 genes under the control of the HCMV major IE promoter (pHD101SV1) (22) was modified by removal of a $1.1-\mathrm{kb}$ HindIII restriction fragment containing the simian virus 40 early promoter-enhancer region. The wild-type, single-site mutant, and double-site mutant DHFR-CAT expression vectors were described previously $(14,41)$ and are shown diagrammatically in Fig. 1A. The pE2-CAT expression vector was described previously (59). Plasmids containing the DHFR wild-type and double-site mutant E2F sites were described earlier (14). A plasmid containing the DHFR single-site mutant E2F site was created by site-directed mutagenesis (56) of plasmid pDHF-239 (83) with a mutagenic oligonucleotide described previously (43). For removal of 


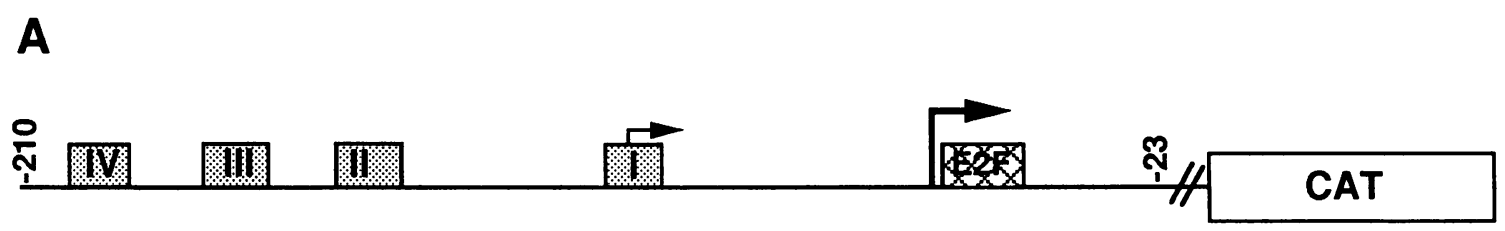

B

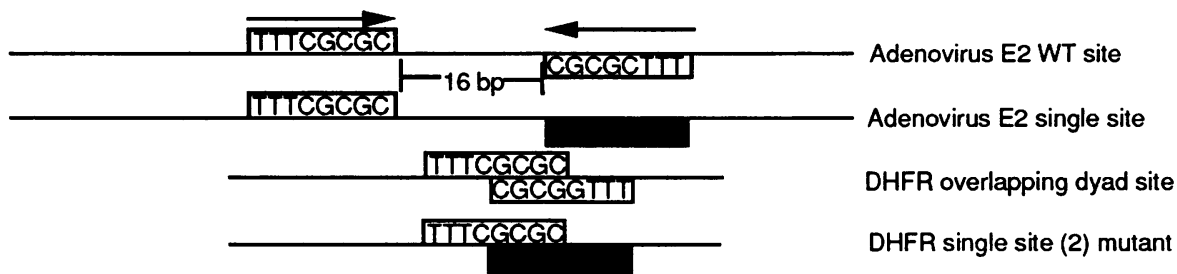

C

\section{CCCGACTGCAATTTCGCGCCAAACTTGGG \\ DHFR E2F WT probe \\ CCCGACTGCAATTTCGATCCAAACTTGGG}

\section{CCCGACTGCAATTTCGCGCCIITCTTGGG}

FIG. 1. Promoter constructs and oligonucleotides. (A) Diagram of the wild-type hamster DHFR promoter-CAT construct showing the sequence elements that have been shown to bind cellular transcription factors. These include GC boxes I, II, III, and IV (stippled boxes) and the overlapping dyad E2F site (cross-hatched box). The major (large arrow) and minor (small arrow) transcription start sites are shown. Numbering is relative to the translation start site, which is +1. (B) Configuration of E2F sites to which E2F binds in wild-type (WT) and mutant adenovirus E2 and DHFR promoters. The adenovirus E2 promoter E2F sites are $16 \mathrm{bp}$ apart and oppositely oriented. The DHFR promoter E2F sites also are oppositely oriented, as shown, but share $4 \mathrm{bp}$ in an overlapping region. Site 1 is the $5^{\prime}$ site on the top strand, while site 2 is the $3^{\prime}$ site on the bottom strand. The single-site (site 2) mutant used in some experiments contains only the $5^{\prime}$ binding site and contains a mutation of the $3^{\prime}$ site identical to that shown for the site 2 mutant (mut) oligonucleotide. (C) Oligonucleotide sequences. A double point mutation, CG to TA, abolishes both DHFR E2F sites in the E2F double-site mutant (E2Fdsmut) probe, to which E2F does not bind. A triple point mutation, AAA to TTT, abolishes the $3^{\prime}$ E2F site in the site 2 mutant probe, but E2F still binds to the 5' E2F site.

the upstream GC boxes, a HindIII-HaeIII fragment containing the single-site mutant E2F site was subcloned into pUC18 cut with HindIII and HincII. Appropriate restriction fragments were labeled with the Klenow fragment, $\left[{ }^{32} \mathrm{P}\right]$ $\mathrm{dATP}$, and/or $\left[{ }^{32} \mathrm{P}\right] \mathrm{dCTP}$.

Methylation interference and missing base contact assays. Partially methylated (at $G$ residues) or depyrimidinated DNA was prepared by treatment of end-labeled probes with dimethyl sulfate or hydrazine, respectively, as described previously (64). The modified probes were added to preparative gel mobility shift reaction mixtures. DNA binding complexes and free probes were resolved by electrophoresis and autoradiography, excised from gels, and eluted in a buffer consisting of $10 \mathrm{mM}$ Tris ( $\mathrm{pH}$ 8.0)-10 mM EDTA-0.2 $\mathrm{M} \mathrm{NaCl}$. The labeled probes were purified through a $0.45-$ $\mu \mathrm{m}$-pore-size Acrodisc filter (Gelman Sciences), loaded onto an Elutip column (Schleicher and Schuell), and eluted from the column with $1.0 \mathrm{M} \mathrm{NaCl}-10 \mathrm{mM}$ Tris (pH 8.0)-10 mM EDTA before ethanol precipitation. The modified probes were cleaved with piperidine and loaded onto denaturing polyacrylamide gels.

\section{RESULTS}

Figure 1A shows a schematic diagram of the hamster DHFR promoter-CAT construct used to assess activation by HCMV infection or by HCMV IE gene products. The E2F site and the three promoter-proximal GC boxes are required for maximum basal transcription and transient expression from the promoter, as determined by previous studies (14, $15,83)$. The major and minor transcription start sites, as demonstrated by primer extension analysis (15), are shown. The E2F double-site mutant promoter used for these assays is identical to this construct, except for a double point mutation that abolishes E2F binding to the site (14); this promoter mutation, CG to TA, is the same as that shown in the DHFR double-site mutant oligonucleotide (Fig. 1C). The DHFR site 2 mutant promoter is identical to the wild-type promoter, except for a triple point mutation that abolishes the 3' E2F site in the overlapping dyad (TTTCGCGCCAAA) but leaves the $5^{\prime}$ E2F site intact; the sequence of this mutant is TTTCGCGCCTTT (underlining indicates the mutation).

The configurations of E2F sites on the wild-type and mutant DHFR and E2 promoter fragments used in gel mobility shift assays are shown in Fig. 1B. Other factor binding sites on the promoters (the DHFR promoter GC boxes and the E2 promoter ATF site) are not included in these fragments. The mutation creating the E2 single-site mutant sequence was described previously (59). The sequences of the oligonucleotides used as competitors in the binding assays are shown in Fig. 1C; the double-site mutation, TTTCGTACCAAA, abolishes E2F binding.

HCMV activation of the DHFR promoter. HCMV can complement an E1A-deficient adenovirus mutant, and activation of the adenovirus E2 promoter is efficiently mediated by products of the HCMV IE 1 and 2 genes $(84,85)$. The 
A

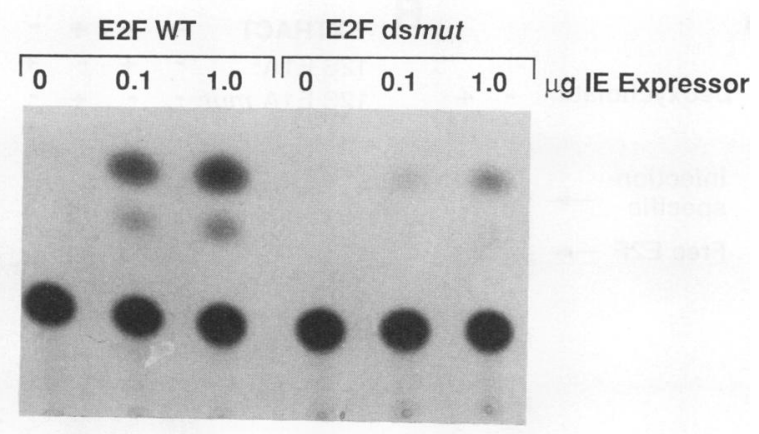

B

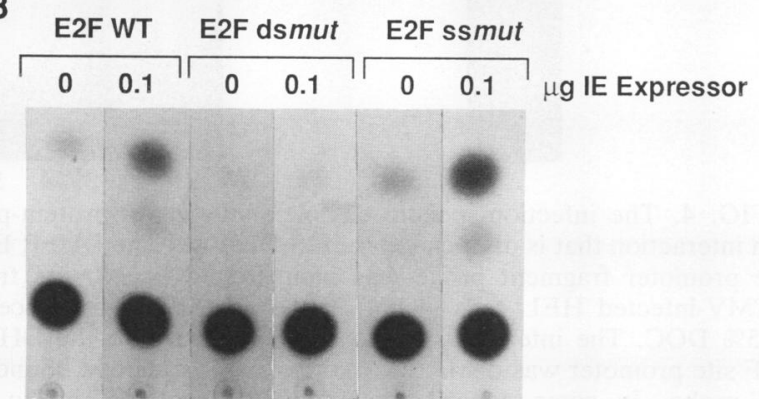

FIG. 2. (A) E2F binding mediates activation by IE gene products. NHF cells were transfected with $5 \mu \mathrm{g}$ of a construct containing either the wild-type (WT) or the double-site mutant (dsmut) DHFR promoter linked to a CAT reporter. Cells were cotransfected with 0 , 0.1 , or $1.0 \mu \mathrm{g}$ of an HCMV IE 1 and 2 expressor plasmid; the total amount of cotransfected DNA was adjusted to $1.0 \mu \mathrm{g}$ with pUC18. Cells were harvested $48 \mathrm{~h}$ after transfection and analyzed for CAT activity. (B) A single E2F site is sufficient for IE activation. Cos-1 cells were transfected with $5 \mu \mathrm{g}$ of a construct containing the wild-type, double-site mutant, or single-site mutant (ssmut) DHFR promoter linked to a CAT reporter. Cells were cotransfected with either 0 or $0.1 \mu \mathrm{g}$ of a plasmid expressing the HCMV IE 1 and 2 gene products.

adenovirus E1A protein activates the DHFR promoter in an E2F-dependent manner (41). We first confirmed that HCMV infection activates an adenovirus E2 promoter-CAT construct and determined that a wild-type DHFR promoterCAT construct was also efficiently activated by HCMV infection (data not shown). We then asked whether HCMV IE 1 and 2 gene products could mediate trans-activation of the DHFR promoter and whether the E2F site was involved in the activation. Figure 2A shows the result of an experiment in which either a control plasmid or the indicated amounts of a plasmid expressing the IE 1 and 2 genes (22) were cotransfected into NHF cells along with a wild-type or E2F double-site mutant DHFR promoter-CAT construct. The wild-type promoter efficiently activated the reporter gene, while little activation was observed in the absence of a functional E2F site.

The experiment depicted in Fig. 2B shows the effects of IE 1 and 2 gene products on expression from the wild-type DHFR promoter and on two E2F site mutant promoters in Cos-1 cells. The wild-type DHFR promoter and the singlesite mutant promoter in which one of the two E2F sites was abolished (Fig. 1B) were efficiently activated by the IE 1 and 2 gene products. However, equivalent amounts of the plasmid expressing IE 1 and 2 gene products failed to activate the double-site mutant promoter, to which E2F does not bind. This result demonstrates that E2F can mediate transactivation of the DHFR gene by HCMV IE 1 and 2 gene products.

Changes in E2F binding activity after HCMV infection. Previously, gel mobility shift assays were used to examine binding to the E2F site of the DHFR promoter in the presence of extracts from HeLa cells (14). To assess the effect of HCMV infection on protein-DNA interactions at the DHFR E2F site, we initially performed gel mobility shift assays using extracts from uninfected NHF cells and from NHF cells harvested 12,40 , and 65 hours postinfection (hpi). The probes for these assays were promoter fragments that contained the wild-type or single-site (site 2) mutant DHFR E2F site or a 29-mer oligonucleotide containing the wild-type DHFR E2F site. Identical gel mobility shift patterns were obtained with each of these probes; furthermore, the patterns of binding in these extracts to E2 promoter fragments containing either one or both E2F sites (Fig. 1B) were also identical (data not shown). These findings demonstrated that a single E2F site, TTTCGCGC, is sufficient for binding and are consistent with the data demonstrating that a single E2F site confers responsiveness to HCMV IE gene products. The results shown in Fig. 3A were obtained with the promoter fragment containing the wild-type DHFR E2F site. In repeated experiments, we observed in uninfected-cell extracts a band that migrated with previously characterized free E2F in HeLa cells. This form of E2F is apparently not complexed with other proteins $(8,14)$. Additionally, we observed in uninfected-cell extracts a more slowly migrating band (lanes 2 and 9) that decreased in intensity after viral infection. This complex may be analogous to a G1-specific complex that has been observed by others $(65,66,77)$ and was further characterized (see Fig. 5).

The most striking change observed in E2F binding after infection was the induction of a complex (marked by an arrowhead adjacent to Fig. 3A, lane 4), which we termed infection specific, in extracts from NHF cells harvested 40 hpi. A more slowly migrating binding activity also was increased in some experiments, but this activity was observed only in NHF cell extracts, was not always reproducible, and was not specific for the E2F site (Fig. 3A, lanes 6 to 8). By $65 \mathrm{hpi}$, all E2F binding activity was markedly reduced; the reason for this is at present unclear. The different E2F complexes obtained with the E2F site probes at different times were not caused simply by variability in the protein quality or DNA binding activity of the extracts, as a control experiment shown in Fig. 3B demonstrates. Binding to a probe containing the recognition sequence for the adenovirus major late transcription factor (MLTF) was not different among these extracts (Fig. 3B, lanes 2 to 5).

In subsequent experiments, we tested E2F binding in mock-infected and HCMV-infected HEL cells. In some experiments, these cells allowed us to resolve more sharply defined complexes, perhaps because of less proteolytic activity, and the infection-specific complex appeared earlier during infection (by $4 \mathrm{hpi}$ ). Otherwise, the corresponding complexes observed in HEL cell extracts were identical, by all criteria tested (see below), to those observed in extracts from NHF cells. The DNA binding complexes observed in mock-infected and 4-hpi HEL cell extracts are shown in Fig. $3 \mathrm{~A}$, lanes 9 and 10, respectively. These results and similar data obtained with a DHFR E2F single-site mutant probe demonstrated that HCMV infection led to an infectionspecific DNA binding activity that appeared to be mediated by a single E2F site.

Characterization of the HCMV infection-specific complex. 


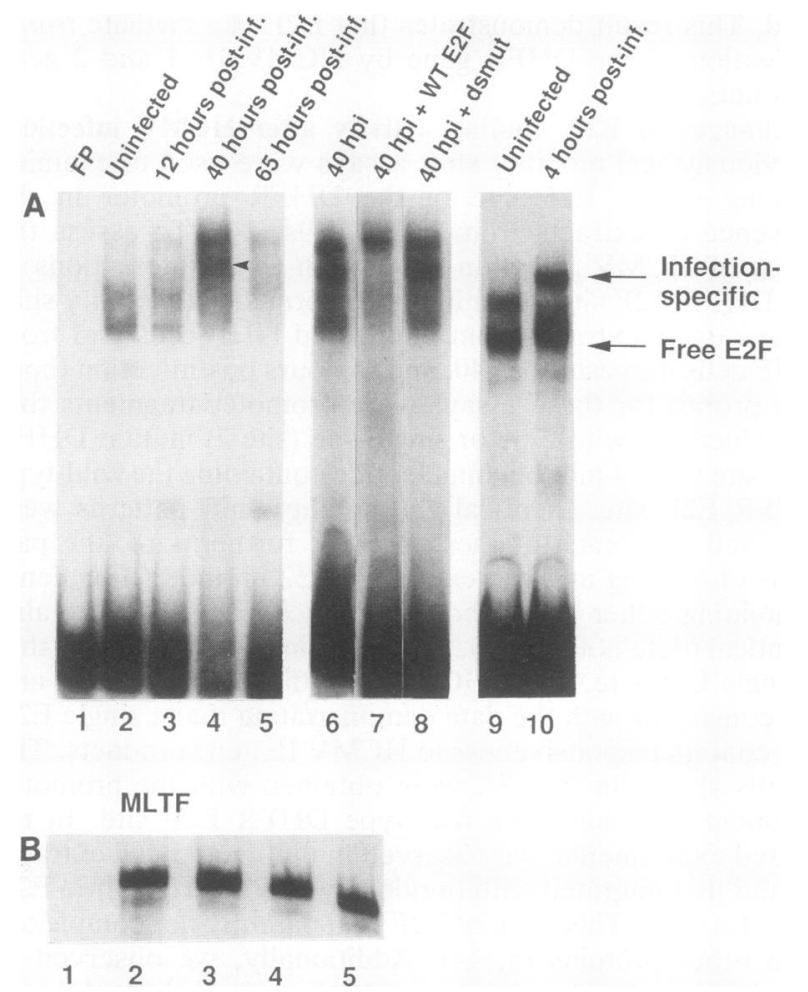

FIG. 3. (A) Protein-DNA complex induced by HCMV infection. Lane 1 (FP) shows the migration of a labeled DHFR promoter fragment incubated in gel mobility shift reaction buffer in the absence of a cell extract. Lanes 2 to 5 show protein-DNA complexes formed in the presence of extracts containing $7 \mu \mathrm{g}$ of protein from uninfected NHF cells or from NHF cells harvested 12, 40, and 65 hpi, respectively; inf., infection. Lanes 6 to 8 show the binding site specificity of the protein-DNA complexes formed in the presence of the 40-hpi NHF cell extract; lane 6 contained no added oligonucleotide. Lane 7 shows competition with a 20 -fold molar excess of the wild-type (WT) DHFR E2F site oligonucleotide. Lane 8 shows competition with a 20 -fold molar excess of the double-site mutant (dsmut) DHFR E2F site oligonucleotide. Lanes 9 and 10 show protein-DNA complexes formed in the presence of extracts from uninfected HEL cells or from HEL cells harvested 4 hpi. Free E2F indicates the band representing the migration of free E2F bound to DNA as previously characterized in experiments with extracts from HeLa cells. The more slowly migrating infection-specific complex is indicated by the arrowhead adjacent to lane 4 and in lane 10 . The complex that was formed in extracts from uninfected cells (lanes 2 and 9), that migrated between the position of free E2F and the infection-specific complex, and that decreased in intensity upon HCMV infection was further characterized (see Fig. 5). (B) Binding in control gel mobility shift reactions to a probe containing the recognition sequence for the adenovirus major late transcription factor (MLTF). Gel mobility shift reactions in the presence of NHF cell extracts were identical to those in the corresponding lanes in panel A.

Two possibilities were immediately suggested by the HCMV-induced binding to the DHFR E2F site. Either the binding of another cellular or viral protein was induced by infection and competed for free E2F binding or at least one additional protein was associated with E2F. Treatment with DOC, which disrupts protein-protein interactions at low concentrations, was previously used to dissociate heteromeric E2F-containing complexes on the E2 promoter, eliminating the more slowly migrating complexes and leaving only free E2F bound to the promoter $(8,65)$. We allowed

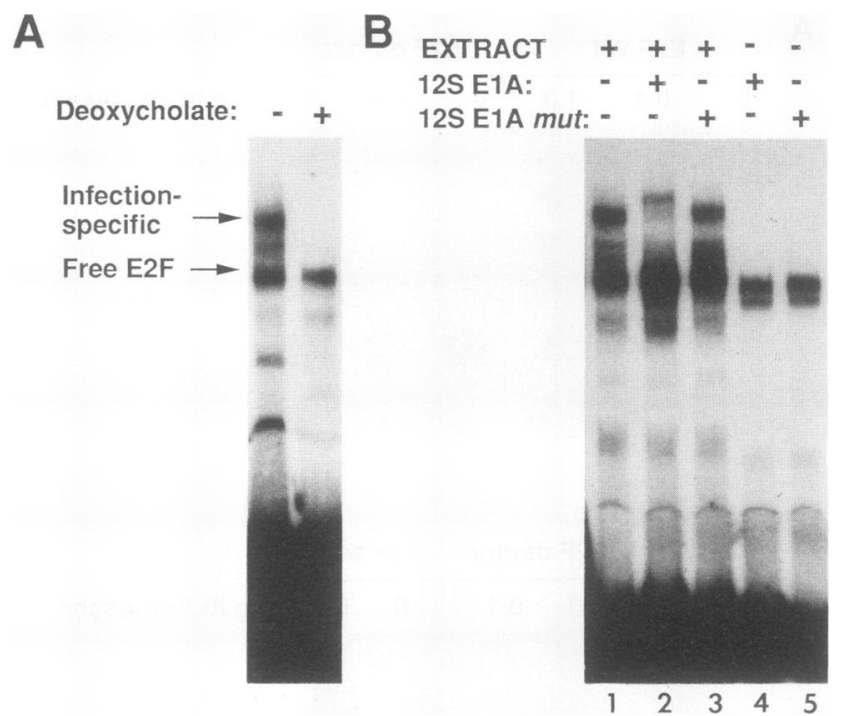

FIG. 4. The infection-specific complex involves a protein-protein interaction that is dissociated by $12 \mathrm{~S}$ E1A. (A) The DHFR E2F site promoter fragment probe was incubated with extracts from HCMV-infected HEL cells (4 hpi) in the absence or presence of $0.25 \%$ DOC. The infection-specific complex bound to the DHFR E2F site promoter was disrupted, and free E2F remained bound to the probe. In some experiments, DOC dissociation led to an increase in free E2F binding activity. (B) A reticulocyte lysate containing in vitro-translated wild-type or mutant (mut) $12 \mathrm{~S}$ E1A protein was added to a gel mobility shift reaction mixture. The wild-type protein (lane 2) but not the mutated protein (lane 3 ) dissociated the HCMV infection-specific complex, releasing free E2F. The supershifted complex visible in lane 2 may represent the binding of 12S E1A to one or more of the proteins in the infectionspecific complex. Lanes 4 and 5 show DNA binding activity in the reticulocyte lysates.

HCMV infection-specific complexes to form on the DHFR E2F site before adding DOC. The results of this experiment are shown in Fig. 4A. DOC treatment eliminated the more slowly migrating complex, suggesting that an infectionspecific protein-protein interaction involving E2F was disrupted.

To further characterize the infection-specific complex, we added a reticulocyte lysate expressing the $12 \mathrm{~S}$ adenovirus E1A protein to gel mobility shift reaction mixtures. The wild-type E1A protein synthesized in this lysate does not contain an amino-terminal activation domain (conserved region 3) found in the 13S E1A product, but the two domains (conserved regions 1 and 2) found in the 12S E1A product have been shown to be sufficient to dissociate heteromeric E2F complexes and release free E2F (73). In the experiment shown in Fig. 4B, the 12S E1A-programmed lysate dissociated the infection-specific complex and increased the level of free E2F binding to the DHFR E2F site in extracts from HCMV-infected HEL cells, confirming that a protein-protein interaction involving E2F led to the infection-specific complex. In addition, we sometimes observed a small amount of a supershifted complex that may represent an interaction between the 12S E1A gene product and one or more of the components of the infection-specific complex. A lysate containing an equal amount of a 12S E1A protein with a single amino acid change resulting from a point mutation in conserved region 2 had no effect on the infection-specific complex. DNA binding activity in each of these lysates alone 


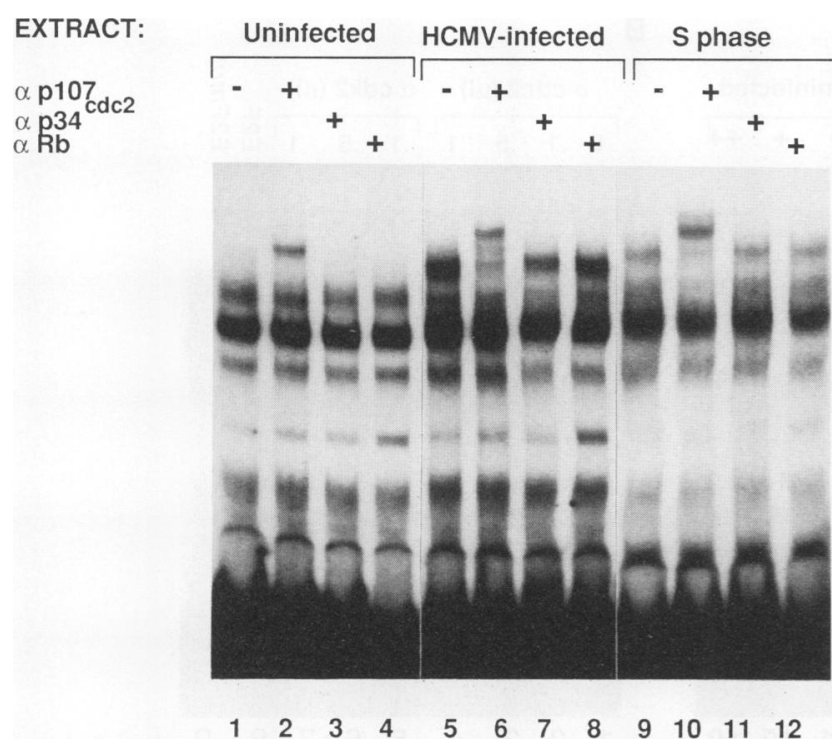

FIG. 5. The p107 protein is associated with E2F in distinct complexes in uninfected cells and in both HCMV-infected and $S$-phase cells. Complexes formed in extracts from mock-infected (lane 1), HCMV-infected (lane 5), and S-phase (lane 9) HEL cells are shown. Affinity-purified antibodies against p107 (lanes 2, 6, and 10) or $\mathrm{p} 34^{c d c^{2}}$ (lanes 3,7 , and 11) were added to gel mobility shift reaction mixtures. The p107 antiserum reduced the intensity of the most slowly migrating complex in each extract and produced a supershifted complex, while neither the p34 cdc2 control antibodies nor a monoclonal antibody against $\mathrm{Rb}$ (lanes 4,8 , and 12 ) had an effect on the complexes.

is shown in Fig. 4B, lanes 4 and 5. The lysates acted identically on NHF cell infection-specific complexes (data not shown).

These results, taken together, demonstrated that at the level of E2F binding, the consequences of HCMV infection were different from those associated with adenovirus infection. Indeed, HCMV infection led to the induction of a heteromeric complex that could be dissociated by the adenovirus E1A protein-a result that is supported by earlier work showing that no infection-specific complex forms on the DHFR E2F site during E1A activation of the DHFR promoter (41). Our gel mobility shift experiments also showed that the HCMV infection-specific complex was identical on wild-type or mutant DHFR and E2 promoters as long as a single E2F site was available for binding; in contrast, the adenovirus infection-specific complex containing E2F and the viral E4 protein is dependent on the presence of two properly spaced and oriented E2F sites and is the only known heteromeric E2F-containing complex that is not dissociated by $\operatorname{E1A}(37,74)$.

Previous studies suggested several possibilities for the identity of proteins in the HCMV infection-specific complex. Because the complex required only a single E2F site, it seemed unlikely that it was mediated by an activity analogous to that of adenovirus E4, which stabilizes the cooperative binding of two E2F molecules to adjacent sites on the E2 promoter $(6,38,49,63,68,75,76)$. However, the HCMV IE 1 protein has been shown to associate with metaphase chromosomes (57), and it was conceivable that this association could be mediated by DNA-bound transcription factors. Alternatively, it was possible that the complex represented an interaction between E2F and a viral protein similar to the hepatitis $B$ virus $X$ or herpes simplex virus VP16 protein, which can activate transcription by forming DNA binding protein-protein complexes with cellular transcription factors $(33,61)$. In several experiments, antibodies against HCMV IE 1 and 2 gene products had no effect on the infection-specific complex when added to gel mobility shift reaction mixtures (data not shown).

Other possibilities for the identity of the infection-specific complex were suggested by observations of cell cycleregulated E2F complexes, which initially were observed in extracts from synchronized mouse BALB/c 3T3 cells (66) and further characterized by a number of groups. Recent studies showed, for example, that two nuclear pocket proteins, $\mathrm{Rb}$ and p107, can interact with E2F in specific DNA binding complexes. A DNA binding complex involving E2F and the G1-associated underphosphorylated form of $\mathrm{Rb}$ has been characterized, and it has been suggested that this form of E2F may exhibit a decreased ability to activate the transcription of genes modulated by E2F $(9,11,20,21,42)$. Because it was possible that HCMV could disrupt an RbE2F complex to activate DHFR, we asked whether Rb was part of an E2F complex that was observed in uninfected cells and that sometimes decreased in intensity upon HCMV infection (Fig. 3, 5, and 6). This complex in uninfected cells, like the infection-specific complex, was dissociated to free E2F by treatment with either DOC or 12S E1A (data not shown). An antibody previously shown to supershift or eliminate E2F-Rb complexes failed to detect $R b$ in complexes from late-log-phase uninfected HEL cells (Fig. 6, lane 4). This antibody also failed to detect $\mathrm{Rb}$ in either the infection-specific complex or the S-phase complex (Fig. 6, lanes 8 and 12), although it did detect $\mathrm{Rb}$ in a mid-log-phase cell population (data not shown).

We then tested each of these cell extracts for the presence of p107 (29), an Rb-related protein that previously had been identified in S-phase E2F complexes $(19,24,78)$. We detected p107 in the complex that migrated more slowly than free E2F in uninfected-cell extracts (Fig. 5, lane 2). An E2F-p107 complex in G1-phase cells also has been observed by at least one other group (77). We also detected p107 in both the HCMV infection-specific complex and the S-phasespecific complex in extracts from HEL cells (Fig. 5, lanes 6 and 10), while neither control antibodies (Fig. 5, lanes 3, 7, and 11) nor normal mouse serum (data not shown) had any effect on the complexes.

Because the p107-containing complexes in S-phase and HCMV-infected cells seemed to comigrate (Fig. 5), we tested the infection-specific complex for the presence of other known components of the S-phase complex. The unexpected presence of the cell cycle regulatory cyclin A protein (72) in an S-phase complex with E2F was first demonstrated in 3T3 cells (65) and confirmed in other cell types by several groups. The addition of an antiserum against the cyclin A protein to gel mobility shift reaction mixtures eliminated the HCMV infection-specific complex (Fig. 6A, lanes 2 and 3), while neither affinity-purified antibodies against cyclin $B$ (lane 4) nor an antiserum against p34 ${ }^{c d c 2}$ (lane 5) affected the complex. Figure 6A, lanes 6 to 10 , confirms the presence of cyclin $A$ in an S-phase extract from HEL cells, and lanes 11 to 13 show controls in which the cyclin $\mathrm{A}$ antiserum was tested against the complexes found in extracts from mock-infected HEL cells. The presence of cyclin A in 40-hpi NHF cell extracts also was confirmed (data not shown).

Another recently described component of S-phase E2F complexes, cyclin A-associated p33 ${ }^{c d k 2}(19,24,26,78,87)$, 


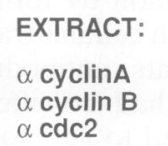

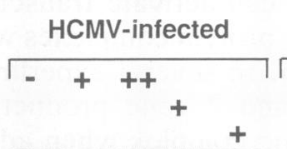
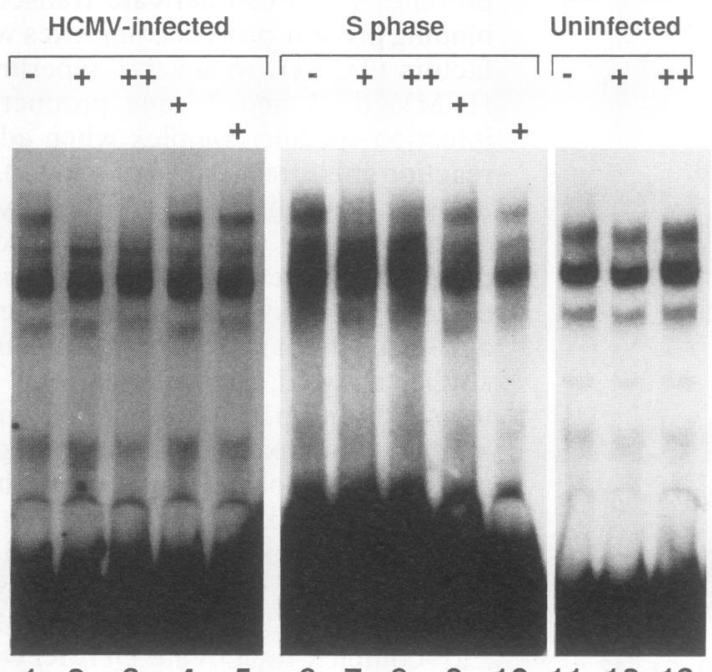

$\begin{array}{lllll}1 & 2 & 3 & 4 & 5\end{array}$

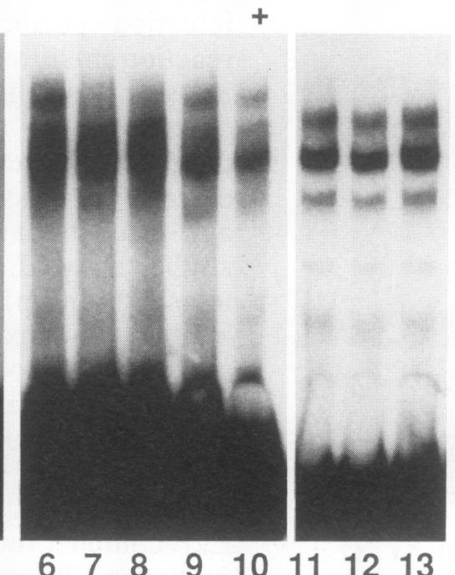

B
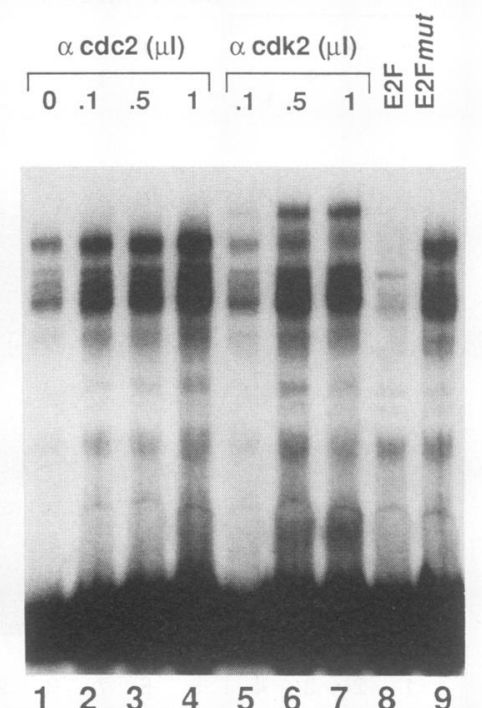

FIG. 6. The infection-specific complex contains cyclin A and $\mathrm{p} 33^{\text {cdk2 }}$. (A) Complexes formed in extracts from HCMV-infected (4-hpi) HEL cells (lanes 1 to 5), S-phase HEL cells (lanes 6 to 10), or mock-infected HEL cells (lanes 11 to 13) are shown. Either 0.1 (lanes 2, 7, and 12) or 0.5 (lanes 3,8 , and 13) $\mu \mathrm{l}$ of cyclin A antiserum was added to gel mobility shift reaction mixtures before electrophoresis, eliminating cyclin A-containing complexes in the HCMV-infected and S-phase extracts. As negative controls, gel mobility shift reaction mixtures were incubated with $200 \mathrm{ng}$ of affinity-purified antibodies against cyclin B (lanes 4 and 9) or $0.5 \mu \mathrm{l}$ of a p34 ${ }^{\text {cdc2 }}$ antiserum (lanes 5 and 10). The reactions shown in lanes 1 to 13 were resolved on the same gel, but different exposures of each set of reactions are shown to visualize the complexes more clearly. (B) Cyclin A-associated p33 ${ }^{c d k 2}$, but not $\mathrm{p} 34^{c d c 2}$, is part of the infection-specific complex. The indicated amounts of antiserum against each kinase were added to gel mobility shift reaction mixtures. Only the p33 ${ }^{\text {cdk2 }}$ antiserum (lanes 5 to 7 ) interacted with the infection-specific complex from HEL cells. The complex was decreased in intensity, and a supershifted complex appeared. The specificity of the complexes was confirmed by competition with wild-type (E2F) or mutant (E2Fmut) E2F site oligonucleotides (lanes 8 and 9). The increase in the intensity of E2F complexes produced by the addition of either antiserum or normal serum also has been observed by others (e.g., 19) and may be caused by a stabilizing effect of serum proteins on E2F complexes.

was also shown to be part of the HCMV infection-specific complex. A rabbit antiserum against $\mathrm{p} 33^{c d k 2}$ (69) effectively supershifted the infection-specific complex (Fig. 6B). A rabbit antiserum against another cell cycle-regulated kinase that can associate with cyclin $\mathrm{A}, \mathrm{p} 34^{\text {cdc2 }}$, had no effect on the infection-specific complex. In the experiment depicted in Fig. 6B, the infection-specific complex tested was from 4-hpi HEL cell extracts. As expected, anti-p33 ${ }^{c d k 2}$ antiserum also interacted with the NHF cell infection-specific complex (data not shown).

Taken together, the binding assays, dissociation experiment, and immunological data identified common characteristics and components for recently characterized S-phase complexes involving the E2F transcription factor and the HCMV infection-specific complexes that we had identified. However, it was possible that there were differences between the infection-specific complexes and the S-phase complexes that were not resolvable in these assays. To test one possible difference-that the HCMV infection-specific complexes changed the DNA base contact points with the E2F binding site from those previously characterized for free E2F (14) and an E2F- and cyclin A-containing complex from mouse $L$ cells $(8)$-we performed methylation interference assays. Figure 7 shows that on either DNA strand, the modified $\mathrm{G}$ residues that interfered with protein binding were identical whether free E2F or the cyclin-containing complexes from HCMV-infected NHF cells were examined. This result was identical to that obtained when the L-cell complex was examined for changes in $\mathrm{G}$ residue contacts (8). A missing base contact assay in which $\mathrm{T}$ and $\mathrm{C}$ residues were modified before protein was allowed to bind to the probes also failed to detect differences in base interactions between free E2F and E2F in the HCMV infection-specific complex (data not shown).

\section{DISCUSSION}

This study shows that HCMV activates the promoter of the cellular DHFR gene. Transcription factor E2F is a mediator for HCMV activation of this promoter by HCMV IE gene products. Also, we show that HCMV infection leads to the induction of a heteromeric DNA binding complex containing E2F, p107, cyclin A, and p33 ${ }^{\text {cdk2 }}$. This complex is similar and possibly identical to a complex previously shown to be characteristic of cells that are in the $S$ phase of the cell cycle $(19,24,65,69)$. These results, therefore, are consistent with earlier findings that suggest that HCMV induces DNA synthesis $(2,4,5,23,32,81,82)$, although we have not established a temporal correlation between the induction of the E2F-p107-cyclin A-p33 ${ }^{\text {cdk2 }}$ complex and any infectioninduced entry of cells into the $S$ phase. The functional role of E2F- and cyclin A-containing complexes has not been demonstrated, and their role may relate to replication, transcription, or even some link between these cellular processes.

Earlier studies showed that several other cellular genes necessary for proliferation or DNA replication are induced by HCMV infection. These include those for DNA polymerase $\alpha(44,46)$, thymidine kinase $(27,90)$, ornithine decarboxylase (50), and topoisomerase II (13). The activation of DHFR, which is required for DNA replication, is therefore consistent with this pattern of gene activation by the virus.

HCMV activation through E2F sites. Our results demon- 


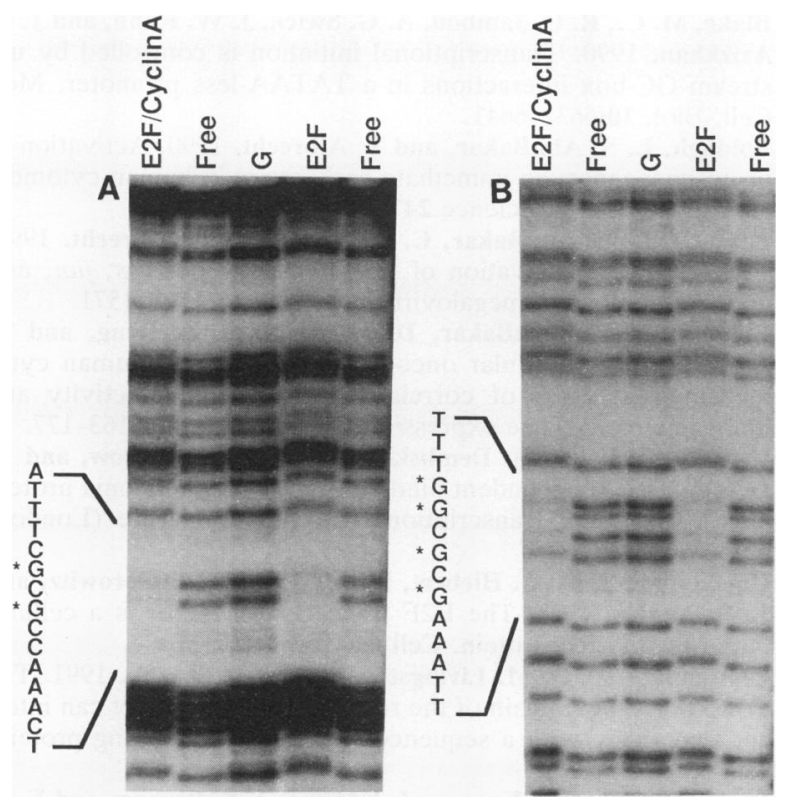

FIG. 7. Methylation interference analysis of the E2F complexes. Methylation of $G$ residues has an identical effect on the binding of free E2F or of a E2F- and cyclin A-containing complex. The top (A) or bottom (B) strand of a DHFR wild-type promoter fragment containing the E2F site was specifically end labeled and partially methylated at $\mathrm{G}$ residues with dimethyl sulfate before being added to scaled-up gel mobility shift reaction mixtures. Bands representing the free probe (free), probe bound to free E2F (E2F), or probe bound to the E2F-cyclin A complex (E2F/cyclin A) were excised from the gel, purified, and cleaved with piperidine before electrophoresis through a denaturing gel. Lane $G$ is a $G$ ladder that confirms the positions of $G$ residues in the promoter sequence. Asterisks show $\mathrm{G}$ residues that interfere with protein bonding.

strate that E2F is required for maximal HCMV activation of the DHFR promoter by products of the HCMV IE 1 and 2 genes. The promoters of at least three HCMV early genes contain potential E2F sites. One of these genes produces a 2.2-kb transcript encoding several proteins by differential splicing, another results in the production of a $2.7-\mathrm{kb}$ mRNA species, and a third is termed UL $84(47,54,55,80,88)$. At least two other cellular genes activated by HCMV, those for DNA polymerase $\alpha(71)$ and c-myc (86), have E2F sites in functionally important regions of their respective promoters. It is important to point out that, like E1A and several other viral immediate early proteins, the HCMV IE gene products are promiscuous trans-activators and can modulate transcription from many promoters that do not contain E2F sites. Additionally, all E2F-containing promoters characterized to date contain binding sites for other transcription factors that may be activated by IE gene products; indeed, we have found that E2F dependence may be affected by factors such as the growth state of cells and that major IE gene products expressed at high levels can provide some activation of the E2F double-site mutant DHFR promoter, possibly through the Sp1 binding sites (data not shown). Nevertheless, we have also shown that a synthetic promoter construct consisting only of a TATA element and a single upstream E2F site can be activated by the HCMV IE 1 and 2 gene products (51), and we suggest that activation through E2F sites by an HCMV IE protein(s) can play an important role in productive $\mathrm{HCMV}$ infection. It has been reported that HCMV IE 2, but not IE 1, can interact directly with and activate transcription through the TATA binding factor TFIID (36), and it is likely that there are distinct interactions among the various IE region gene products and specific transcription factors or components of the general transcriptional machinery.

Infection-induced complexes. The induction of infectionspecific complex formation may simply be the result of the ability of HCMV to induce cellular DNA synthesis. However, our data demonstrate that at the molecular level, the effect of HCMV infection on interactions among several cell cycle-regulated proteins bound via E2F to a cellular promoter is different from the effect of adenovirus infection, even though both viruses activate the transcription of many of the same cellular genes and induce cellular DNA synthesis. It is clear that many important questions-including determination of the functional role of the E2F-p107-cyclin A-p33 ${ }^{c d k 2}$ complex during the cell cycle and during viral infection-require more study. E2F recently has been cloned independently by two groups on the basis of its ability to bind directly to $\mathrm{Rb}(39,52)$, allowing experiments to address these questions more directly.

It will also be important to determine whether the expression of products of the HCMV major IE genes is sufficient both for the formation of the infection-specific complex and for the decrease in intensity of the E2F-p107 complex observed in uninfected cells. It has been suggested that a variety of physiological effects of HCMV infection which resemble the responses of cells to growth factors occur independently of IE gene expression and may be due to signal pathways induced by the binding of the virus particle to the cell $(2,3)$. Although our results show that E2F is involved in the activation of the DHFR promoter by HCMV IE gene products, it is possible that the formation of the E2F-p107-cyclin A-p33 $3^{\text {cdk2 }}$ complex is related to an HCMVinduced signal pathway that is independent of IE gene expression and its effect on DHFR expression. It is also possible that HCMV IE proteins interact directly with one or more components of the E2F complexes. Adenovirus E1A protein has been shown to bind directly to $\mathrm{p} 33^{c d k 2}$, cyclin A, $\mathrm{p} 107, \mathrm{Rb}$, and other cellular proteins, some of which also bind directly to one another and to E2F (e.g., 19, 28, 30, 87). The HCMV IE 2 protein also interacts directly with a number of cellular proteins, and these interactions may be functionally analogous to those between E1A and cellular proteins (31).

Recent work has shown that HCMV induces the expression of the cellular proto-oncogenes $m y c$, fos, and jun, with kinetics slightly different from those induced by serum (16-18). Furthermore, it has long been known that HCMV perturbs the cell cycle and can lead to chromosome damage $(1,53,60,67)$. A careful comparison of E2F complex binding during HCMV infection and the normal cell cycle could provide clues about possible mechanisms for these effects and for the function of E2F complexes. We are attempting to determine whether the temporal differences in the induction of complex formation that we observed between HEL and NHF cells relate to subtle differences between the cell types or the condition of the cells at the time of HCMV infection or to other factors. These differences, as well as the ability to study synchronized growing fibroblasts, should allow for temporal comparisons among complex formation, the initiation of cellular DNA synthesis, and transcriptional induction of genes modulated by E2F. Therefore, complexes induced by HCMV infection could be useful in determining a functional role for the cyclin-kinase complex that appears to be 
anchored to gene promoters during the $\mathrm{S}$ phase and, as we have now shown, during HCMV infection.

\section{ACKNOWLEDGMENTS}

We are grateful to Al Baldwin, Michael Blake, Shelton Earp, Ed Harlow, Tony Hunter, Robert Jambou, Joseph Nevins, and members of the Nevins laboratory for helpful discussions. We thank Virginia Kraus for E1A expression plasmids, S.-M. Huong and Jeanne Kahn for expert technical assistance, and Michele Pagano, Pidder Jansen-Durr, Jim Schwarz, Li-Hueh Tsai, Ed Harlow, Marlene Dembski, Nick Dyson, Tony Hunter, Jonathon Pines, Ray Jupp, and Jay Nelson for very kind gifts of antisera or antibodies and advice.

This work was supported in part by American Cancer Society grant CD317C and a March of Dimes basic research grant to J.C.A. and by NIH grants AI12727 and CA21773 to E.-S.H. T.F.K. was supported by Damon Runyon-Walter Winchell Cancer Research Fund fellowship DRG-1097. M.M. was supported by the Howard Hughes Medical Institute. M.W. was supported by an NIH training grant and by the North Carolina Institute of Nutrition.

\section{REFERENCES}

1. AbuBakar, S., W. W. Au, M. S. Legator, and T. Albrecht. 1988. Induction of chromosome aberrations and mitotic arrest by cytomegalovirus in human cells. Environ. Mol. Mutagen. 12: $409-420$.

2. Albrecht, T., I. Boldogh, M. Fons, C. H. Lee, S. AbuBakar, J. M. Russell, and W. W. Au. 1989. Cell-activation responses to cytomegalovirus infection: relationship to the phasing of CMV replication and to the induction of cellular damage. Subcell. Biochem. 15:157-202.

3. Albrecht, T., M. P. Fons, I. Boldogh, S. AbuBakar, C. Z. Deng, and D. Millinofi. 1991. Metabolic and cellular effects of human cytomegalovirus infection. Transplant. Proc. 3(Suppl. 3):48-55.

4. Albrecht, T., M. Nachtigal, J. S. St. Jeor, and F. Rapp. 1976. Induction of cellular DNA synthesis and increased mitotic activity in Syrian hamster embryo cells abortively infected with human cytomegalovirus. J. Gen. Virol. 30:167-177.

5. Albrecht, T., and F. Rapp. 1973. Malignant transformation of hamster embryo fibroblasts following exposure to ultravioletirradiated human cytomegalovirus. Virology 55:53-61.

6. Babiss, L. E. 1989. The cellular transcription factor E2F requires viral E1A and E4 gene products for increased DNAbinding activity and functions to stimulate adenovirus E2A gene expression. J. Virol. 63:2709-2717.

7. Bagchi, S., P. Raychaudhuri, and J. R. Nevins. 1989. Phosphorylation-dependent activation of the adenovirus-inducible E2F transcription factor in a cell-free system. Proc. Natl. Acad. Sci. USA 86:4352-4356.

8. Bagchi, S., P. Raychaudhuri, and J. R. Nevins. 1990. Adenovirus E1A proteins can dissociate heteromeric complexes involving the E2F transcription factor: a novel mechanism for E1A trans-activation. Cell 62:659-669.

9. Bagchi, S., R. Weinmann, and P. Raychaudhuri. 1991. The retinoblastoma protein copurifies with E2F-I, an E1A-regulated inhibitor of the transcription factor E2F. Cell 65:1063-1072.

10. Bandara, L. R., J. P. Adamczewski, T. Hunt, and T. N. La. 1991. Cyclin A and the retinoblastoma gene product complex with a common transcription factor. Nature (London) 352:249-251.

11. Bandara, L. R., and T. N. La. 1991. Adenovirus Ela prevents the retinoblastoma gene product from complexing with a cellular transcription factor. Nature (London) 351:494-497.

12. Bauerle, P. A., and D. Baltimore. 1988. Activation of DNAbinding activity in an apparently cytoplasmic precursor of the NF- $\mathrm{kB}$ transcription factor. Cell 53:211-217.

13. Benson, J. D., and E. S. Huang. 1990. Human cytomegalovirus induces expression of cellular topoisomerase II. J. Virol. 64:915.

14. Blake, M. C., and J. C. Azizkhan. 1989. Transcription factor E2F is required for efficient expression of the hamster dihydrofolate reductase gene in vitro and in vivo. Mol. Cell. Biol. 9:4994-5002.
15. Blake, M. C., R. C. Jambou, A. G. Swick, J. W. Kahn, and J. C. Azizkhan. 1990. Transcriptional initiation is controlled by upstream GC-box interactions in a TATAA-less promoter. Mol. Cell. Biol. 10:6632-6641.

16. Boldogh, I., S. AbuBakar, and T. Albrecht. 1990. Activation of proto-oncogenes: an immediate early event in human cytomegalovirus infection. Science 247:561-564.

17. Boldogh, I., S. AbuBakar, C. Z. Deng, and T. Albrecht. 1991. Transcriptional activation of cellular oncogenes fos, jun, and $m y c$ by human cytomegalovirus. J. Virol. 65:1568-1571.

18. Boldogh, I., S. AbuBakar, D. Millinoff, C. Z. Deng, and T. Albrecht. 1991. Cellular oncogene activation by human cytomegalovirus. Lack of correlation with virus infectivity and immediate early gene expression. Arch. Virol. 118:163-177.

19. Cao, L., B. Faha, M. Dembski, L.-H. Tsai, E. Harlow, and N. Dyson. 1992. Independent binding of the retinoblastoma protein and p107 to the transcription factor E2F. Nature (London) 355:176-179.

20. Chellappan, S. P., S. Hiebert, M. Mudryj, J. M. Horowitz, and J. R. Nevins. 1991. The E2F transcription factor is a cellular target for the RB protein. Cell 65:1053-1061.

21. Chittenden, T., D. M. Livingston, and W. J. Kaelin. 1991. The T/E1A-binding domain of the retinoblastoma product can interact selectively with a sequence-specific DNA-binding protein. Cell 65:1073-1082.

22. Davis, M. G., S. C. Kenney, J. Kamine, J. S. Pagano, and E. S. Huang. 1987. Immediate-early gene region of human cytomegalovirus trans-activates the promoter of human immunodeficiency virus. Proc. Natl. Acad. Sci. USA 84:8642-8646.

23. DeMarchi, J. M. 1983. Correlation between stimulation of host cell DNA synthesis by human cytomegalovirus and lack of expression of a subset of early virus genes. Virology 129:274 286.

24. Devoto, S. H., M. Mudryj, J. Pines, T. Hunter, and J. R. Nevins. 1992. A cyclin A-protein kinase complex possesses sequencespecific DNA binding activity: p33cdk2 is a component of the E2F-cyclin A complex. Cell 68:167-176.

25. Dignam, J. D., R. M. Lebovitz, and R. G. Roeder. 1983. Accurate transcription initiation by RNA polymerase II in a soluble extract from isolated mammalian nuclei. Nucleic Acids Res. 11:1475-1489.

26. Elledge, S. J., and M. R. Spottswood. 1991. A new human p34 protein kinase, CDK2, identified by complementation of a cdc28 mutation in Saccharomyces cervevisiae, is a homolog of Xenopus Eg1. EMBO J. 10:2653-2661.

27. Estes, J. E., and E. S. Huang. 1977. Stimulation of cellular thymidine kinases by human cytomegalovirus. J. Virol. 24:1321.

28. Ewen, M. E., B. Faha, E. Harlow, and D. M. Livingston. 1992. Interaction of p107 with cyclin A independent of complex formation with viral oncoproteins. Science 255:85-87.

29. Ewen, M. E., Y. Xing, J. B. Lawrence, and D. M. Livingston. 1991. Molecular cloning, chromosomal mapping and expression of the cDNA for p107, a retinoblasoma gene product-related protein. Cell 66:1155-1164.

30. Faha, B., M. E. Ewen, L.-H. Tsai, D. M. Livingston, and E. Harlow. 1992. Interaction between human cyclin A and adenovirus E1A-associated p107 protein. Science 255:87-90.

31. Furnari, E., and E.-S. Huang. Unpublished data.

32. Geder, K. M., R. Lausch, F. O'Neill, and F. Rapp. 1976. Oncogenic transformation of human embryo lung cells by human cytomegalovirus. Science 192:1134-1137.

33. Gerster, T., and R. G. Roeder. 1988. A herpesvirus transactivating protein interacts with transcription factor OTF-1 and other cellular proteins. Proc. Natl. Acad. Sci. USA 86:63476351 .

34. Gorman, C., L. F. Moffat, and B. H. Howard. 1982. Recombinant genomes which express chloramphenicol acetyltransferase in mammalian cells. Mol. Cell. Biol. 2:1044-1051.

35. Graham, F. L., and A. J. van der Eb. 1973. Transformation of rat cells by DNA of human adenovirus 5. Virology 54:536-539.

36. Hagemeier, C., S. Walker, R. Caswell, T. Kouzarides, and J. Sinclair. 1992. The human cytomegalovirus 80-kilodalton but 
not the 72-kilodalton immediate-early protein transactivates heterologous promoters in a TATA box-dependent mechanism and interacts directly with TFIID. J. Virol. 66:4452-4456.

37. Hardy, S., D. A. Engel, and T. Shenk. 1989. An adenovirus early region 4 gene product is required for induction of the infectionspecific form of cellular E2F activity. Genes Dev. 3:1062-1074.

38. Hardy, S., and T. Shenk. 1989. E2F from adenovirus-infected cells binds cooperatively to DNA containing two properly oriented and spaced recognition sites. Mol. Cell. Biol. 9:44954506.

39. Helin, K., J. A. Lees, M. Vidal, N. Dyson, E. Harlow, and A. Fattaey. 1992. A cDNA encoding a pRB-binding protein with properties of the transcription factor E2F. Cell 70:337-350.

40. Hermiston, T. W., C. L. Malone, P. R. Witte, and M. F. Stinski. 1987. Identification and characterization of the human cytomegalovirus immediate-early region 2 gene that stimulates gene expression from an inducible promoter. J. Virol. 61:3214-3221.

41. Hiebert, S. W., M. Blake, J. Azizkhan, and J. R. Nevins. 1991. Role of E2F transcription factor in E1A-mediated trans activation of cellular genes. J. Virol. 65:3547-3552.

42. Hiebert, S. W., S. P. Chellapan, J. M. Horowitz, and J. R. Nevins. 1992. The interaction of RB with E2F coincides with an inhibition of the transcriptional activity of E2F. Genes Dev. 6:177-185.

43. Hiebert, S. W., M. Lipp, and J. R. Nevins. 1989. E1A-dependent trans-activation of the human MYC promoter is mediated by the E2F factor. Proc. Natl. Acad. Sci. USA 86:3594-3598.

44. Hirai, K., and Y. Watanabe. 1976. Induction of alpha type DNA polymerases in human cytomegalovirus-infected WI-38 cells. Biochim. Biophys. Acta 447:328-339.

45. Hu, Q., C. Bautista, G. M. Edwards, D. Defeo-Jones, R. E. Jones, and E. Harlow. 1991. Antibodies specific for the human retinoblastoma protein identify a family of related polypeptides. Mol. Cell. Biol. 11:5792-5799.

46. Huang, E.-S. 1975. Human cytomegalovirus. III. Virus-induced DNA polymerase. J. Virol. 16:298-310.

47. Huang, E. S. Unpublished data.

48. Huang, E. S., S. T. Chen, and J. S. Pagano. 1973. Human cytomegalovirus. I. Purification and characterization of viral DNA. J. Virol. 12:1473-1481.

49. Huang, M. M., and P. Hearing. 1989. The adenovirus early region 4 open reading frame $6 / 7$ protein regulates the DNA binding activity of the cellular transcription factor, E2F, through a direct complex. Genes Dev. 3:1699-1710.

50. Isom, H. J. 1979. Stimulation of ornithine decarboxylase by human cytomegalovirus. J. Gen. Virol. 42:265-278.

51. Jupp, R., J. Nelson, M. Wade, and J. Azizkhan. Unpublished data.

52. Kaelin, W. G., Jr., W. Krek, W. R. Sellers, J. A. DeCaprio, F. Ajchenbaum, C. S. Fuchs, T. Chittenden, Y. Li, P. J. Farnham, M. A. Blanar, D. M. Livingston, and E. K. Flemington. 1992. Expression cloning of a cDNA encoding a retinoblastoma binding protein with E2F-like properties. Cell 70:351-364.

53. Kamiya, S., J. Tanaka, T. Ogura, H. Ogura, H. Sato, and M. Hatano. 1986. Rabbit kidney cells abortively infected with human cytomegaloviruses are arrested in mitotic phase. Arch. Virol. 89:131-144.

54. Klucher, K. M., D. K. Rabert, and D. H. Spector. 1989. Sequences in the human cytomegalovirus 2.7-kilobase RNA promoter which mediate its regulation as an early gene. J. Virol. 63:5334-5343.

55. Klucher, K. M., and D. H. Spector. 1990. The human cytomegalovirus 2.7-kilobase RNA promoter contains a functional binding site for the adenovirus major late transcription factor. $J$. Virol. 64:4189-4198.

56. Kunkel, T. A., J. D. Roberts, and R. A. Zakour. 1987. Rapid and efficient site-specific mutagenesis without phenotypic selection. Methods Enzymol. 154:367-382.

57. Lafemina, R. L., M. C. Pizzorno, J. D. Mosca, and G. S. Hayward. 1989. Expression of the acidic nuclear immediateearly protein (IE1) of human cytomegalovirus in stable cell lines and its preferential association with metaphase chromosomes. Virology 172:584-600.
58. Lipp, M., R. Schilling, and G. Bernhardt. 1989. trans-activation of human MYC: the second promoter is target for the stimulation by adenovirus Ela proteins. Oncogene 4:535-541.

59. Loeken, M. R., and J. Brady. 1989. The adenovirus EIIA enhancer. Analysis of regulatory sequences and changes in binding activity of ATF and EIIF following adenovirus infection. J. Biol. Chem. 264:6572-6579.

60. Luleci, G., M. Skizli, and A. Gunalp. 1980. Selective chromosomal damage caused by human cytomegalovirus. Acta Virol. 24:341-345.

61. Maguire, H. F., J. P. Hoeffler, and A. Siddiqui. 1991. HBV X protein alters the DNA binding specificity of CREB and ATF-2 by protein-protein interactions. Science 252:842-844.

62. Malone, C. L., D. H. Vesole, and M. F. Stinski. 1990. Transactivation of a human cytomegalovirus early promoter by gene products from the immediate early gene IE2 and augmentation by IE1: mutational analysis of the viral proteins. J. Virol. 64:1498-1506.

63. Marton, M. J., S. B. Baim, D. A. Ornelles, and T. Shenk. 1990. The adenovirus E4 17-kilodalton protein complexes with the cellular transcription factor E2F, altering its DNA-binding properties and stimulating E1A-independent accumulation of E2 mRNA. J. Virol. 64:2345-2359.

64. Maxam, A. M., and W. Gilbert. 1980. Sequencing end-labeled DNA with base-specific chemical cleavages. Methods Enzymol. 65:499-560.

65. Mudryj, M., S. H. Devoto, S. W. Hiebert, T. Hunter, J. Pines, and J. R. Nevins. 1991. Cell cycle regulation of the E2F transcription factor involves an interaction with cyclin A. Cell 65:1243-1253.

66. Mudryj, M., S. W. Hiebert, and J. R. Nevins. 1990. A role for the adenovirus inducible E2F transcription factor in a proliferation dependent signal transduction pathway. EMBO J. 9:2179_ 2184.

67. Natchtigal, M., and S. Natchtigal. 1978. Interactions between human herpesviruses and host cell chromosomes. Arch. Roum. Pathol. Exp. Microbiol. 7:223-249.

68. Neill, S. D., C. Hemstrom, A. Virtanen, and J. R. Nevins. 1990. An adenovirus E4 gene product trans-activates E2 transcription and stimulates stable E2F binding through a direct association with E2F. Proc. Natl. Acad. Sci. USA 87:2008-2012.

69. Pagano, M., G. Draetta, and P. Jansen-Durr. 1992. Association of cdk2 kinase with the transcription factor E2F during S phase. Science 255:1144-1147.

70. Pagano, M., R. Pepperkok, F. Verde, W. Ansorge, and G. Draetta. 1992. Cyclin A is required at two points in the human cell cycle. EMBO J. 11:961-971.

71. Pearson, B. E., H.-P. Nasheuer, and T. S.-F. Wang. 1991. Human DNA polymerase $\alpha$ gene: sequences controlling expression in cycling and serum-stimulated cells. Mol. Cell. Biol. 11:2081-2095

72. Pines, J., and T. Hunter. 1990. Human cyclin A is adenovirus E1A-associated protein p60 and behaves differently from cyclin B. Nature (London) 346:760-763.

73. Raychaudhuri, P., S. Bagchi, S. H. Devoto, V. B. Kraus, E. Moran, and J. R. Nevins. 1991. Domains of the adenovirus E1A protein required for oncogenic activity are also required for dissociation of E2F transcription factor complexes. Genes Dev. 5:1200-1211.

74. Raychaudhuri, P., S. Bagchi, S. D. Neill, and J. R. Nevins. 1990. Activation of the E2F transcription factor in adenovirus-infected cells involves E1A-dependent stimulation of DNA-binding activity and induction of cooperative binding mediated by an E4 gene product. J. Virol. 64:2702-2710.

75. Reichel, R., I. Kovesdi, and J. R. Nevins. 1988. Activation of a preexisting cellular factor as a basis for adenovirus E1Amediated transcription control. Proc. Natl. Acad. Sci. USA 85:387-390.

76. Reichel, R., S. D. Neill, I. Kovesdi, M. C. Simon, P. Raychaudhuri, and J. R. Nevins. 1989. The adenovirus E4 gene, in addition to the E1A gene, is important for trans-activation of E2 transcription and for E2F activation. J. Virol. 63:3643-3650.

77. Schwarz, J., and J. R. Nevins. Unpublished data. 
78. Shirodkar, S., M. Ewen, J. A. DeCaprio, J. Morgan, D. M. Livingston, and T. Chittenden. 1992. The transcription factor E2F interacts with the retinoblastoma product and a p107-cyclin A complex in a cell cycle-regulated manner. Cell 68:157-166.

79. Spector, D. J., and M. J. Tevethia. 1986. Identification of a human cytomegalovirus virus DNA segment that complements an adenovirus 5 immediate early mutant. Virology 151:329-338.

80. Staprans, S. I., D. K. Rabert, and D. H. Spector. 1988. Identification of sequence requirements and trans-acting functions necessary for regulated expression of a human cytomegalovirus early gene. J. Virol. 62:3463-3473.

81. St. Jeor, S. C., T. B. Albrecht, F. D. Funk, and F. Rapp. 1974 Stimulation of cellular DNA synthesis by human cytomegalovirus. J. Virol. 13:353-362.

82. St. Jeor, S. C., and R. Hutt. 1977. Cell DNA replication as a function in the synthesis of human cytomegalovirus. J. Gen. Virol. 37:65-73.

83. Swick, A. G., M. C. Blake, J. W. Kahn, and J. C. Azizkhan. 1989. Functional analysis of GC element binding and transcription in the hamster dihydrofolate reductase gene promoter. Nucleic Acids Res. 17:9291-9304.

84. Tevethia, M. J., and D. J. Spector. 1984. Complementation of an adenovirus 5 immediate early mutant by human cytomegalovirus. Virology 137:428-431.

85. Tevethia, M. J., D. J. Spector, K. M. Leisure, and M. F. Stinski. 1987. Participation of two human cytomegalovirus immediate early gene regions in transcriptional activation of adenovirus promoters. Virology 161:276-285.

86. Thalmeier, K., H. Synovzik, R. Mertz, E. L. Winnacker, and M. Lipp. 1989. Nuclear factor E2F mediates basic transcription and trans-activation by Ela of the human MYC promoter. Genes Dev. 3:527-536.

87. Tsai, L.-H., E. Harlow, and M. Meyerson. 1991. Isolation of the human cdk2 gene that encodes the cyclin A- and adenovirus E1A-associated p33 kinase. Nature (London) 353:174-177.

88. Wright, D. A., and D. H. Spector. 1989. Posttranscriptional regulation of a class of human cytomegalovirus phosphoproteins encoded by an early transcription unit. J. Virol. 63:3117-3127.

89. Wright, D. A., S. I. Staprans, and D. H. Spector. 1988. Four phosphoproteins with common amino termini are encoded by human cytomegalovirus AD169. J. Virol. 62:331-340.

90. Zavada, V., V. Erban, D. Rezacova, and V. Vonka. 1976. Thymidine kinase in cytomegalovirus infected cells. Arch. Virol. 52:333-339. 